\title{
Hardening Contribution of G-Phase Nanoparticle Precipitation and Spinodal Decomposition in Aged Duplex Stainless Steel Studied by APT Analysis and Micro- Hardness of Ferrite
}

\author{
R.Badyka $^{1}$, S.Saillet ${ }^{2}$, C.Domain ${ }^{2}$, G. Monnet $^{2}$ and C.Pareige ${ }^{1}$ \\ 1. Groupe de Physique des Matériaux, UMR 6634 CNRS, Université de Rouen Normandie et INSA de \\ Rouen Normandie, France. \\ 2. EDF R\&D Département Matériaux et Mécanique des Composants, Ecuelles, France.
}

Duplex stainless steels (DSS) used in primary circuit of $2^{\text {nd }}$ generation nuclear power plant endure thermal ageing at service temperature $\left(285^{\circ} \mathrm{C}-325^{\circ} \mathrm{C}\right)$. It has been known for a very long time that these steels are prone to thermal ageing. The ageing impacts the mechanical properties (toughness decreases and hardness increases). The evolution of the mechanical properties depends on the DSS composition [1-4]. Mo-free grades which also contain a smaller amount of nickel than Mo-bearing ones were shown to age less $[1-3,5]$. The ageing of DSS steels is attributed to the decomposition of the ferrite: spinodal decomposition into regions enriched in iron $(\alpha)$ and regions enriched in chromium $(\alpha)$ and precipitation of G-phase particles enriched in $\mathrm{Ni}, \mathrm{Si}, \mathrm{Mn}$ and Mo when present. It appears to be important to know the contribution of each phase on hardening. This contribution is still not evaluated. If everybody in the literature agrees on the fact that spinodal decomposition is the main contributor, disagreements exist on the role of G-phase particles: some authors show a minor role of G-phase particles whereas others claim the inverse [6,7]. The aim of this paper is to quantify the relative contribution of spinodal decomposition and G-phase particles on hardness.

This work links microstructural characterization performed using atom probe tomography to microhardness of the ferrite for a wide variety of duplex steels (from cast steels with and without Mo to lean steels) aged under different conditions. Owing to the combination of the hardening model developed by Ardell [8] for spinodal decomposition and the one of Monnet [9] for G-phase precipitation, we quantify for the first time the contribution of both mechanism of phase separation on hardening of the ferrite in austeno-ferritic steels. The model developed works whatever the occurrence or not of one of the two phase transformation mechanisms.. The micro-hardness increase obtained with the model give an excellent estimation of the experimental values. Owing to this work, the apparent contradiction reported in the literature on the role of the G-phase is clarified and explained. And very importantly, this works shows the contribution of the G-phase is important.

\section{References:}

[1] A. Trautwein, W. Gysel, Int. Cast Met. J. 6 (1981), p. 43.

[2] S. Bonnet et al, Mater. Sci. Technol. 6 (1990), p. 221.

[3] H.M. Chung, T.R. Leax, Mater. Sci. Technol. 6 (1990), p. 249.

[4] J.J. Shiao et al, J. Nucl. Mater. 217 (1994), p. 269.

[5] C.Pareige et al J. Nucl. Mater. 465 (2015), p. 383.

[6] F. Danoix, et al, Appl. Surf. Sci 67 (1993), p. 348.

[7] H.M. Chung, O.K Chopra, Argonne National Lab. (1987).

[8] A.J Ardell, Metall. Trans. A. 16 (1985), p. 2131.

[9] G. Monnet, Acta Mater. 95 (2015), p. 302. 


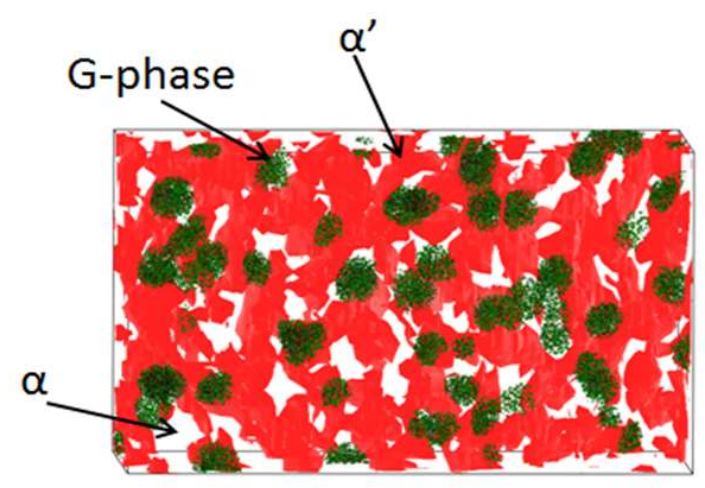

Figure 1. Microstructure obtained by atom probe in aged ferrite, V=30. $30.50 \mathrm{~nm}^{3}$.
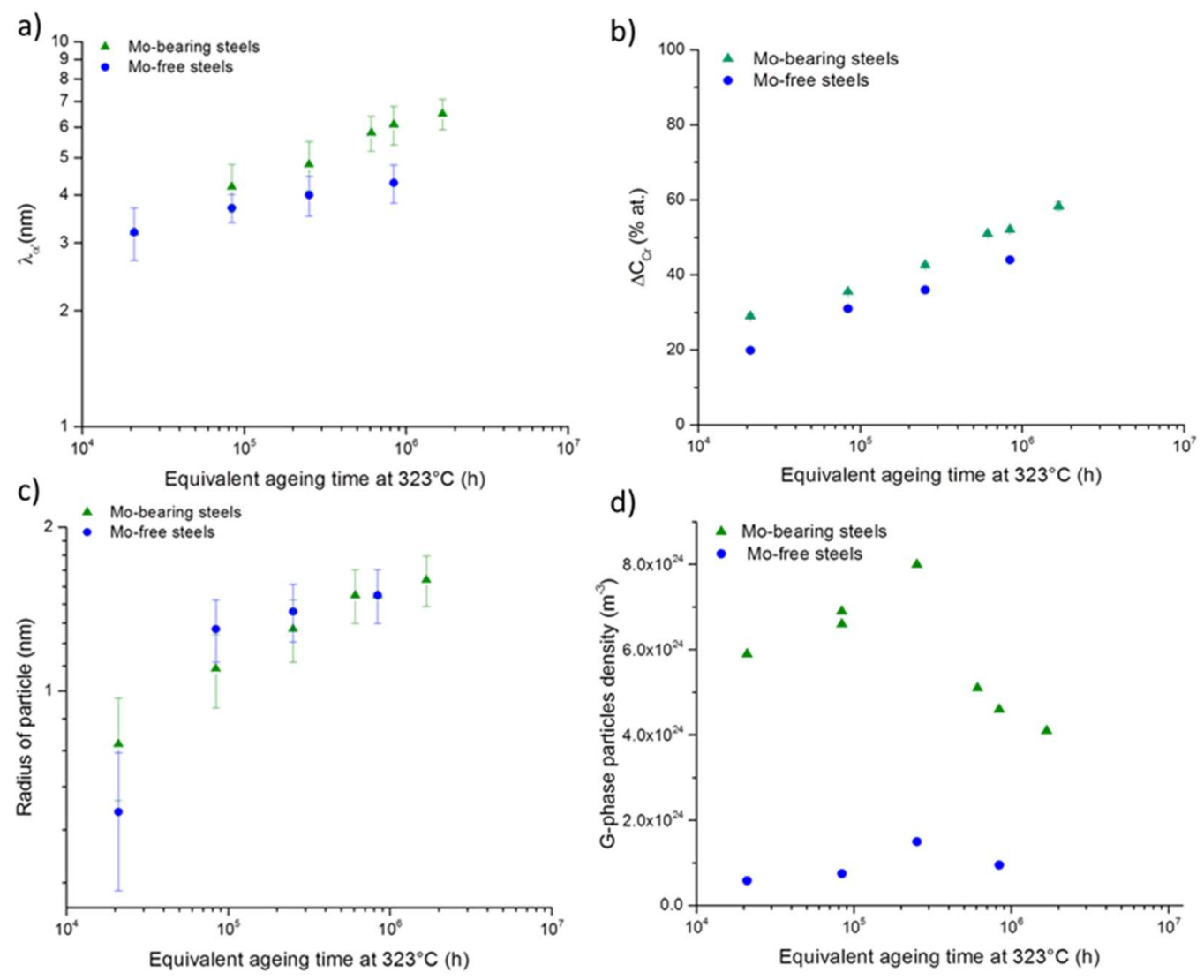

Figure 2. Time evolution of the mean wavelength (a), and amplitude of $\mathrm{Cr}$ concentration (b) of the spinodal decomposition, evolution of the radius (c), and the number density (d) of G phase particles in the ferrite of Mo-bearing steels, green triangle, and Mo-free steel, blue circles. 